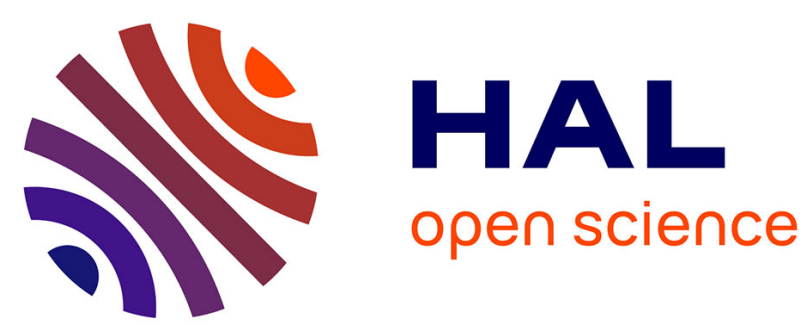

\title{
Effective modulation of the photoluminescence properties of 2,1,3-benzothiadiazoles and 2,1,3-benzoselenadiazoles by Pd-catalyzed $\mathrm{C}-\mathrm{H}$ bond arylations
}

Imane Idris, Thibault Tannoux, Fazia Derridj, Vincent Dorcet, Julien Boixel, Véronique Guerchais, Jean-François Soulé, Henri Doucet

\section{To cite this version:}

Imane Idris, Thibault Tannoux, Fazia Derridj, Vincent Dorcet, Julien Boixel, et al.. Effective modulation of the photoluminescence properties of 2,1,3-benzothiadiazoles and 2,1,3-benzoselenadiazoles by Pd-catalyzed C-H bond arylations. Journal of Materials Chemistry C, 2018, 6 (7), pp.1731-1737. $10.1039 / \mathrm{c} 7 \mathrm{tc0} 0395 \mathrm{a}$. hal-01863972

HAL Id: hal-01863972

https://hal-univ-rennes1.archives-ouvertes.fr/hal-01863972

Submitted on 29 Aug 2018

HAL is a multi-disciplinary open access archive for the deposit and dissemination of scientific research documents, whether they are published or not. The documents may come from teaching and research institutions in France or abroad, or from public or private research centers.
L'archive ouverte pluridisciplinaire HAL, est destinée au dépôt et à la diffusion de documents scientifiques de niveau recherche, publiés ou non, émanant des établissements d'enseignement et de recherche français ou étrangers, des laboratoires publics ou privés. 


\title{
Effective Modulation of 2,1,3-Benzothiadiazoles and 2,1,3- Benzoselenadiazoles Photoluminescence Properties by Pd- Catalyzed C-H Bond Arylations
}

\author{
Imane Idris, ${ }^{a, b}$ Thibault Tannoux, ${ }^{a}$ Fazia Derridj, ${ }^{b}$ Vincent Dorcet, ${ }^{a}$ Julien Boixel, ${ }^{a}{ }^{a}$ * Veronique \\ Guerchais, ${ }^{a}$ Jean-François Soulé, ${ }^{a, *}$ and Henri Doucet ${ }^{\mathrm{a}}$

\begin{abstract}
A one step procedure towards 4-aryl-2,1,3-benzothiadiazoles, 4,7-diaryl-2,1,3-benzothiadiazoles and 4-aryl-2,1,3benzoselenadiazoles using palladium-catalyzed regioselective $\mathrm{C}-\mathrm{H}$ bond arylations of 2,1,3-benzothiadiazole and 2,1,3benzoselenadiazole was developed. A donor-acceptor compound was also synthetized via two successive $\mathrm{C}-\mathrm{H}$ bond arylations at $\mathrm{C} 4$ and $\mathrm{C} 7$ positions of the 2,1,3-benzothiadiazole unit. One of the major achivement of this methodoly refer from the fine modulation of the fluorescence wavelength with emission colors covering the blue to the red part of the visible spectrum by the simple introduction of the suitable aryl group on the 2,1,3-benzothiadiazole unit.
\end{abstract}

\section{Introduction}

Organic functional materials are finding more and more applications. Among them $\pi$-systems of polycyclic aromatic or heteroaromatic compounds such as 2,1,3-benzothiadiazole and 2,1,3-benzoselenadiazole are being actively investigated as cheap replacement of traditional inorganic semiconductors for the development of organic light-emitting diodes (OLED), ${ }^{1}$ organic photovoltaics (OPV) ${ }^{2}$ and bioprobes for bioimaging analyses. $^{3} \quad$ These strong electron acceptor heterocycles represent a pivotal framework for the construction of organic donor-acceptor (D-A) dyes. ${ }^{4}$ As example, in 2005, Ho and coworkers developed a new class of organics dyes (compound I) based on benzothiadiazole and benzoselenadiazole chromophores, which display a good power conversion efficiency (Figure 1, left). ${ }^{5}$ Benzothiadiazoles are also used as acceptor units in donor acceptor (D-A) conjugated polymers, such as the polymer solar cell II (Figure 1 , middle). ${ }^{6}$

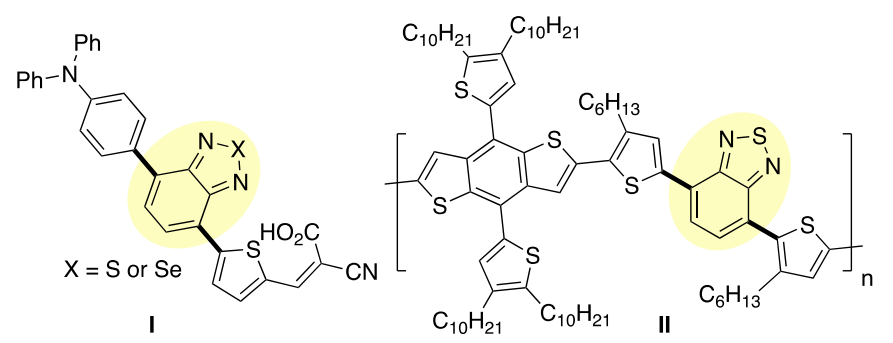

Figure 1. Examples of Useful Molecules Containing 4-Aryl-Benzothiadiazole or 4-ArylBenzoselenadiazole Units.
Despite these wide applications of 4-aryl-substituted 2,1,3benzoselenadiazoles and 2,1,3-benzoselenadiazoles, their synthesis remains challenging and often requires multi-steps synthesis. Protocols involving bromination followed by palladium catalyzed Suzuki, ${ }^{7}$ Stille, $^{8}$ or Hiyama $^{7 a,}{ }^{9}$ crosscoupling reactions are the most commonly employed (Figure 2a). Negishi reactions using an organozinc reagent prepared from benzofurazan through a magnesiation with bis $(2,2,6,6$ tetramethylpiperidin-1-yl)magnesium-lithium chloride complex $\left(\mathrm{TMP}_{2} \mathrm{Mg} \cdot 2 \mathrm{LiCl}\right)$ followed by transmetalation with zinc chloride, have also been reported (Figure 2b). ${ }^{10}$ Since the discovery by Nakamura ${ }^{11}$ and Otha ${ }^{12}$ of the Pd-catalyzed $\mathrm{C}-\mathrm{H}$ bond arylation of heteroarenes using aryl halides, this methodology has emerged as one of the most reliable for the eco-friendly formation of $\mathrm{C}-\mathrm{C}$ bonds for the access to a wide variety of arylated heterocycles. ${ }^{13}$ In 2013, Marder and coworkers reported the first example of $\mathrm{C}-\mathrm{H}$ bond activation of 5,6-difluoro-2,1,3-benzothiadiazole using $10 \mathrm{~mol} \% \mathrm{Pd}(\mathrm{OAc})_{2}$ associated to $20 \mathrm{~mol} \%$ di-tert-butyl(methyl)phosphonium tetrafluoroborate (Figure 2c). ${ }^{14}$ However, 2,1,3benzothiadiazole was not reactive under these reactions conditions, demonstrating the huge impact of fluorine atom in Pd-catalyzed $\mathrm{C}-\mathrm{H}$ arylations via concerted-metalation deprotonation pathway. ${ }^{15}$ This $\mathrm{C}-\mathrm{H}$ bond protocol was then applied in polymerization using dibromobenzene derivatives, ${ }^{16}$ and for the synthesis of organic dyes containing electron-rich (donor) and electron-poor (acceptor) sections. ${ }^{17}$ An example of direct arylation at C4 position of 5-fluoro-2,1,3benzothiadiazole has also been reported. ${ }^{18}$ Latter, Marder and co-workers extended the substrate scope to other electron deficient 2,1,3-benzoselenadiazoles such as 5,6dicyano- and 5,6-dinitro-substituted ones (Figure 2d). ${ }^{19}$ To our knowledge there is no report on direct arylation, via a metalcatalyzed $\mathrm{C}-\mathrm{H}$ bond activation, of unsubstituted 2,1,3benzothiadiazole and 2,1,3-benzoselenadiazoles. Recently, we disclosed that phosphine-free palladium acetate catalyzes the $\mathrm{C}-\mathrm{H}$ bond arylation of benzofurazan (Figure 2e). ${ }^{20}$ Therefore, we decided to investigate the reactivity of unsubstituted 2,1,3benzothiadiazole and 2,1,3-benzoselenadiazole in palladium- 
catalyzed $\mathrm{C}-\mathrm{H}$ bond arylation for the straightforward access to 4-arylated 2,1,3-benzothiadiazoles and 2,1,3benzoselenadiazoles (Figure 2e).

a. Synthesis of 4-Aryl 2,1,3-Benzothiadiazoles and 2,1,3-Benzoselenadiazoles Through Cross-Coupling Reactions ${ }^{7-9}$

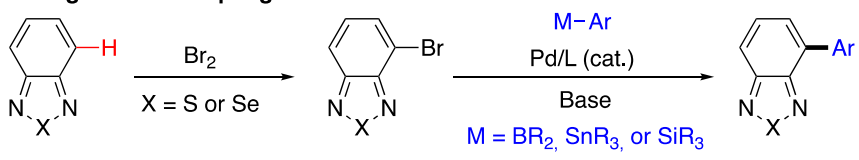

b.-Synthesis of 4-Aryl 2,1,3-Benzothiadiazoles Through Negishi Couplings ${ }^{10}$

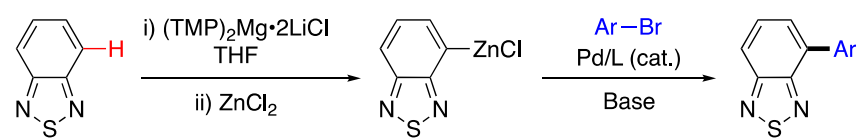

c. Pd-Catalyzed Direct Arylation of 5,6-Difluoro-2,1,3-Benzothiadiazole (Marder) $^{14}$

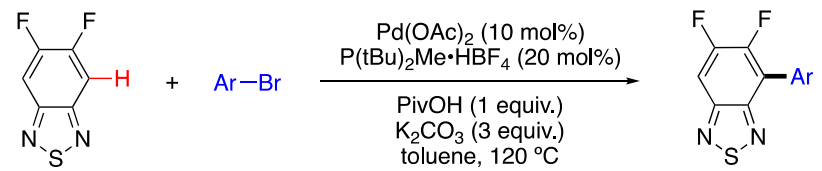

d. Pd-Catalyzed Direct arylation of 2,1,3-Benzothiadazole-5,6-dicarbonitrile and 5,6-Dinitro-2,1,3-benzothiadiazole (Marder) ${ }^{19}$
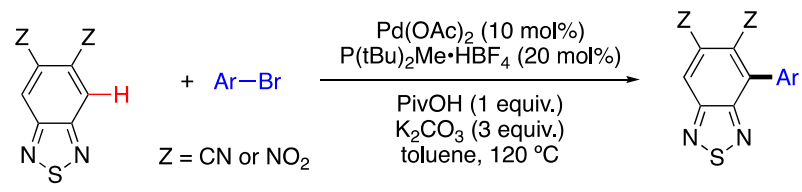

e. Pd-Catalyzed Direct Arylation of Benzofurazan (our group) ${ }^{20}$

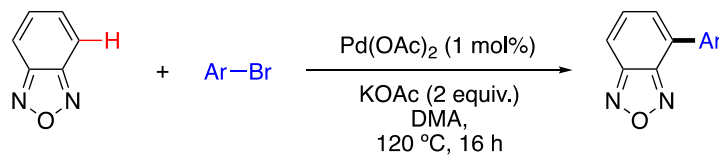

f. Pd-Catalyzed Direct Arylation of 2,1,3-Benzothiadiazole and 2,1,3-Benzoselenadiazole (this work)

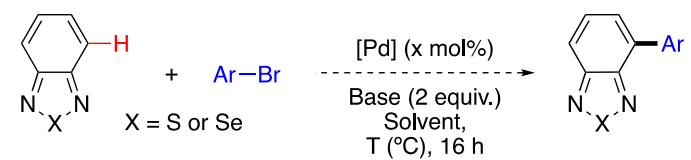

Figure 2. Previous Strategies to Synthetize 4-Aryl 2,1,3-Benzothiadiazoles and 2,1,3Benzoselenadiazoles

\section{Results and Discussion}

Based on our recent results on palladium-catalyzed direct arylation of benzofurazan using aryl bromides as aryl source, ${ }^{20}$ we examined the reactivity of 2,1,3-benzothiadiazole (Table 1). Using our previously reported reaction conditions, namely 1 mol\% $\mathrm{Pd}(\mathrm{OAc})_{2}$ in the presence of KOAc in DMA at $120 \stackrel{\circ}{ } \mathrm{C}$, no reaction occurred between 2,1,3-benzothiadiazole and 4bromobenzonitrile (Table 1, entry 1 ). Using a higher reaction temperature (i.e. $150 \stackrel{\circ}{\circ}$ ), arylated 2,1,3-benzothiadiazole 1, resulting from $\mathrm{C}-\mathrm{H}$ bond activation at the $\mathrm{C} 4$ position, was obtained in $52 \%$ yield (Table 1 , entry 2 ). When the reaction was performed in the presence of $\mathrm{K}_{2} \mathrm{CO}_{3}$ as base, no reaction occurred; while the used of potassium pivalate (PivOK) and potassium adamantane-1-carboxylate $\left(\mathrm{AdCO}_{2} \mathrm{~K}\right)$ allowed the formation of 1 in $84 \%$ and $65 \%$ yields, respectively. Other palladium sources were evaluated (Table 1 , entries 6-8). $\mathrm{PdCl}_{2}$ displayed a similar reactivity than $\mathrm{Pd}(\mathrm{OAc})_{2}$, as the arylated product 1 was isolated in $82 \%$ yield (Table 1 , entry 6). Palladium dimer complex $\left[\mathrm{Pd}\left(\mathrm{C}_{3} \mathrm{H}_{5}\right) \mathrm{Cl}\right]_{2}$ gave a slightly lower yield in 1 of $72 \%$ (Table 1, entry 7). A diphosphine palladium catalysts such as $\mathrm{PdCl}\left(\mathrm{C}_{3} \mathrm{H}_{5}\right)(\mathrm{dppb})$ did not allow to increase the yield compared to phosphine-free procedure (Table 1, entry 8).

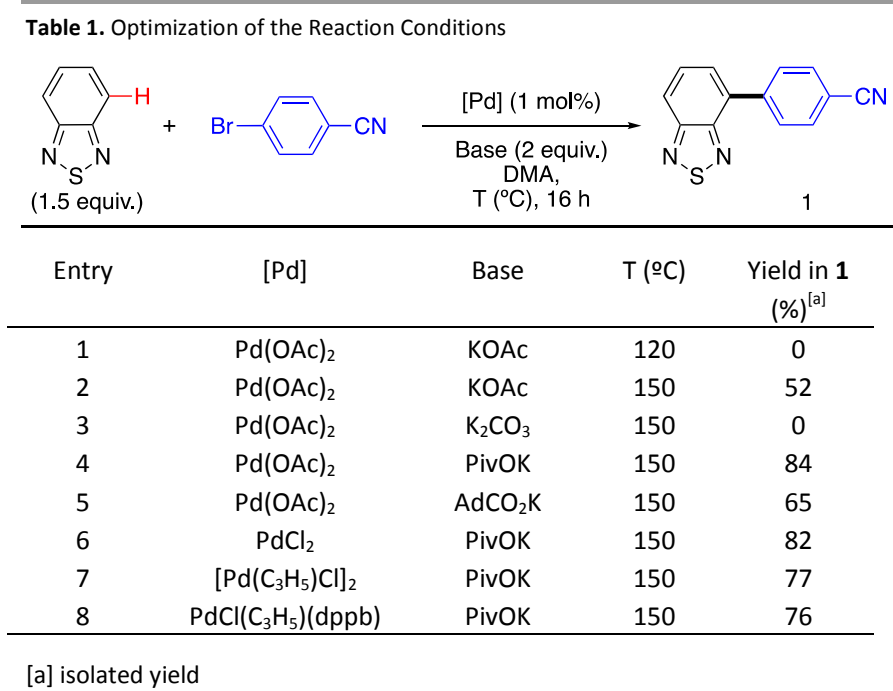

With the best conditions in hands, namely 1 mol\% phosphinefree $\mathrm{Pd}(\mathrm{OAc})_{2}$ associated to PivOK as base in DMA at 150 으, we payed close attention to the scope of the reaction (Scheme 1). First, we examined the reactivity of para-substituted aryl bromides. Electron-deficient 4-bromonitrobenzene, 4bromobenzaldehyde, ethyl 4-bromobenzoate, 4bromopropiophenone and 4-bromobenzophenone reacted nicely to deliver the 4-arylated 2,1,3-benzothiadiazoles 2-6 in $65-74 \%$ yields. 1-Bromo-4-chlorobenzene displayed a lower reactivity, as the desired product 7 was isolated in only $55 \%$ yield, due to the formation of a side product arising from the homocoupling of this aryl bromide. It should be noted that under these reaction conditions, the $\mathrm{C}-\mathrm{Cl}$ bond did not react. Bromobenzene, 1-bromo-4-(tert-butyl)benzene and 4bromoanisole have been successfully employed using this phosphine-free palladium coupling to give $\mathbf{8 - 1 0}$ in $60 \%-65 \%$ yields. A meta-substituent on the aryl bromide had almost no effect, as the desired arylated products 11-14 were obtained in good yields from 3-bromobenzonitrile, 1-bromo-3(trifluoromethyl)benzene, 3-bromonitrobenzene, and 1bromo-3-chlorobenzene. The reaction was almost not sensitive to the steric hindrance, as ortho-substituted aryl bromides such as 2-bromobenzonitrile, and 2bromobenzaldehyde afforded the desired products $\mathbf{1 5}$ and $\mathbf{1 6}$ in good yields. 1,3-Benzodioxol motif has been introduced on the 2,1,3-benzothiadiazole 17, which was isolated in $45 \%$ yield from 2,1,3-benzothiadiazole and 5-bromo-1,3-benzodioxole. Then, in order to show the potential of this method for the preparation of organic materials, we employed some 
extended aryl bromides as coupling partners. 2Bromonaphthalene was efficiently coupled with 2,1,3benzothiadiazole affording 18 in 60\% yield. Its X-ray diffraction analysis confirmed the structure. ${ }^{21}$ 3-Bromofluorene and 1bromopyrene smoothly reacted allowing the formation of the 4-arylated 2,1,3-benzothiadiazoles 19 and 20 in 56\% and 43\% yields, respectively. $\mathrm{N}$-containing heteroaryl bromides (e.g., 2 bromo-6-methoxypyridine, 2-bromo-6(trifluoromethyl)pyridine, or 3-bromoquinoline) also nicely reacted to afford the desired products 21-23 in good yields.

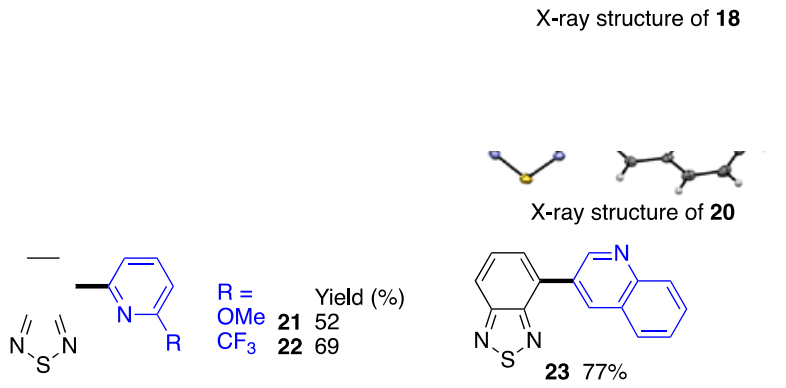

Scheme 1. Scope of Aryl Bromides in Palladium-Catalyzed Direct C4 Arylation of 2,1,3Benzothiadiazole

Next, we investigated the formation of symmetrical 4,7-diaryl2,1,3-benzothiadiazoles (Scheme 2). Using 3 equivalents of 1bromo-4-chlorobenzene and 1 equivalent of 2,1,3benzothiadiazole in the presence of 1 mol\% $\mathrm{Pd}(\mathrm{OAc})_{2}$ associated to 3 equivalents of PivOK in DMA at $150 \stackrel{\circ}{ } \mathrm{C}$, we were pleased to isolate 4,7-bis(4-chlorophenyl)-2,1,3benzothiadiazole (24) as the major product in $64 \%$ yield. From 1-bromo-3-(trifluoromethyl)benzene and 1-bromo-3,5bis(trifluoromethyl)benzene, the 4,7-bis(aryl)-2,1,3benzothiadiazoles $\mathbf{2 5}$ and $\mathbf{2 6}$ were synthetized in good yields. The regioselectivity of the diarylation was confirmed by X-ray diffraction analysis of $26^{[21]}$

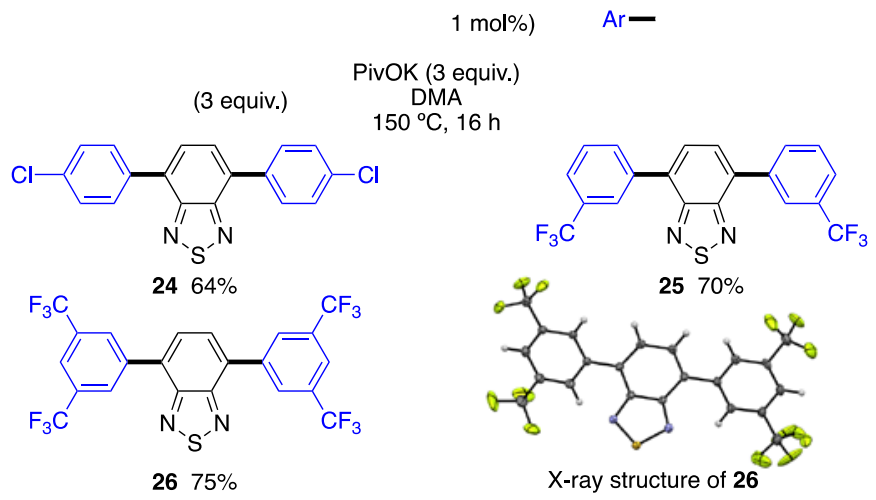

Scheme 2. Scope of Aryl Bromides in Palladium-Catalyzed C4,C7 Diarylation of 2,1,3Benzothiadiazole.

Using this methodology, we also carried out the straightforward synthesis of an unsymmetrical 4,7-diaryl-2,1,3benzothiadiazole via two successive $\mathrm{Pd}$-catalyzed $\mathrm{C}-\mathrm{H}$ bond arylations (Scheme 3). Starting from 17, a second arylation using 1-bromo-3,5-bis(trifluoromethyl)benzene afforded the 4,7-unsymmetrical diaryl 2,1,3-benzothiadiazole 28 in 38\% yield, which should display push-pool properties.

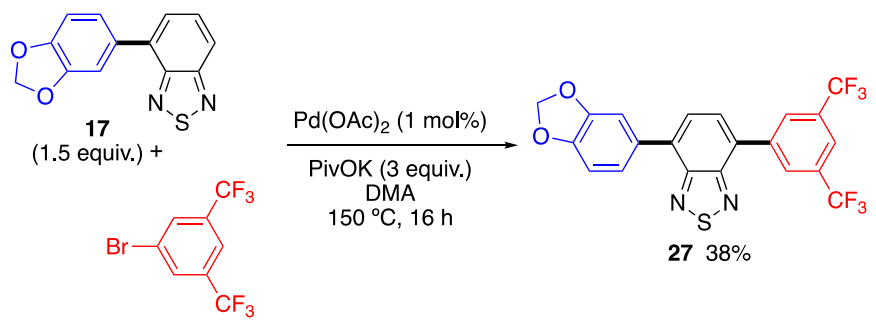

Scheme 3. Example of Synthesis of a "Push-Pull" 4,7-Unsymmetrical Diaryl 2,1,3benzothiadiazole by Iterative Palladium-Catalyzed $\mathrm{C}-\mathrm{H}$ Bond Arylations

Syntheses of selenium containing compounds and the further utilization of these compounds in organic synthesis for the preparation of organic materials attracted less attention. ${ }^{22}$ While a wide variety of thiadiazole containing compounds are known, on the contrary, a limited number of selenadiazoles containing compounds have been prepared. ${ }^{23}$ Therefore, we turned our attention to the reactivity of 2,1,3benzoselenadiazole in $\mathrm{Pd}$-catalyzed $\mathrm{C}-\mathrm{H}$ bond arylation (Scheme 4). For these reactions, we employed the same reaction conditions than for direct arylation of 2,1,3benzothiadaziole, namely, $1 \mathrm{~mol} \% \mathrm{Pd}(\mathrm{OAc})_{2}$ associated with PivOK as base in DMA at 150 ㄷ. Using 4-bromobenzonitrile, 1bromo-4-(tert-butyl)benzene and 1-bromo-3,5bis(trifluoromethyl)benzene, we successfully prepared the 4aryl-2,1,3-benzoselenadiazoles $\mathbf{2 8 - 3 0}$ in $52-57 \%$ yields. The regioselectivity of the arylation of 2,1,3-benzoselenadiazole was confirmed by X-ray diffraction analysis of $30 .{ }^{[21]}$ It should be noted that the reactions with 2,1,3-benzoselenadiazole are more sluggish than the reactions with 2,1,3-benzothiadiazole giving some unidentified decomposition products, which might explain that arylated products are obtained in lower yields. 


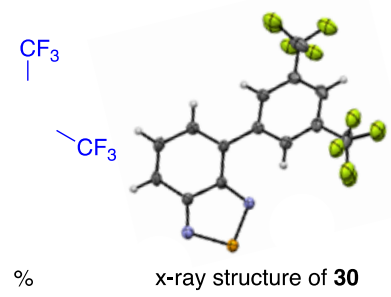

Scheme 4. Scope of Aryl Bromides in Palladium-Catalyzed Direct C4 Arylation of 2,1,3 Benzoselenadiazole

Finally, in order to determine the interest of these new compounds as chromophores, preliminary photophysical studies have been conducted. UV-visible absorption spectra of the mono-substituted $\mathbf{9}, \mathbf{1 7}, \mathbf{1 9}, \mathbf{2 0}$ and the di-substituted 24, 26, 27 2,1,3-benzothiadiazoles, and the benzoselenadiazole derivative $\mathbf{2 9}$ were recorded in dichloromethane solution at room temperature, (see Figures 3 and 4) and the corresponding data are summarized in Table 2. As common feature for all the investigated compounds, their electronic absorption spectra exhibit characteristic set of absorption bands for benzothiadiazole and benzoselenadiazole derivatives, with intense and well-resolved absorption bands in the UV region, from 250 to $350 \mathrm{~nm}$, together with a moderately intense and broad absorption band tailing up in the visible region of the spectrum. The mono-substituted 2,1,3-benzothiadiazole 9, bearing a tert-butyl group on the aryl substituent is considered as a reference compound for the studied series. ${ }^{24}$ The absorption spectrum of 9 shows, in the UV region, a broad band centered at $250 \mathrm{~nm}$ and well-resolved bands from 280 to $325 \mathrm{~nm}$, while at lower energy a weaker and broad band which tails up to $420 \mathrm{~nm}$ is observed (Figure 3 ). According to previous studies, the UV absorption bands of 9 arises from ${ }^{1}\left(\pi-\pi^{*}\right)$ transitions of the $p$-tert-butylphenyl substituent and the benzothiadiazole core, respectively. ${ }^{24 c}$ At lower energy, from 325 to $420 \mathrm{~nm}$, the broad absorption band is assigned to charge transfer transition (CT) from the electrondonating aryl substituent to the $\pi^{*}$ accepting benzothiadiazole moiety. ${ }^{24 c}$ Replacing the $p$-tert-butylaryl substituent by the benzodioxole in 17, red-shifts the CT transition of $50 \mathrm{~nm}$, as a result of larger electron-donating properties of the dioxole group. In comparison with 9, the fluorene-based 2,1,3benzothiadiazole 19 exhibits higher absorptivity within the whole spectrum, due to additional ${ }^{1}\left(\pi-\pi^{*}\right)$ transitions of this $\pi$ extended system but with no significant shift of the absorption bands. Similarly, replacing the fluorenyl (19) by a pyrenyl group (20), gives rise to very intense absorption bands in the UV region, the absorption profile of the benzothiadiazole core being overlapped by the intense and well-resolved absorption bands of the pyrene moiety. The pyrene moiety in $\mathbf{2 0}$ induces a small red-shifted of the CT band $(\Delta \lambda=15 \mathrm{~nm})$, compared with the fluorene substituent in 19 . Based on previous experimental and theoretical studies of benzothiadiazole derivatives, the observed spectral changes by incorporation of various aromatic substituents can be interpreted as a modification of the highest-occupied molecular orbital (HOMO) while the lowest-unoccupied molecular orbital (LUMO), centered on the core, stays almost unchanged. ${ }^{24 c}$ In other words, increasing the electron-richness (17) and/or extension of the $\pi$-system $(\mathbf{1 9}, \mathbf{2 0})$ destabilize the HOMO energy level resulting in a decrease of the HOMO-LUMO gap with respect to 9. As far as the di-substituted 2,1,3benzothiadiazoles are concerned, compounds $\mathbf{2 4}$ bearing two p-chlorophenyl and 26 having with two 3,5bis(trifluoromethyl)aryl groups, exhibit similar absorption profiles with a blue-shift of the charge-transfer band in 24, compare to 26, attributed to the strong electron-withdrawing $\mathrm{CF}_{3}$ groups (Figure 4). As expected, the compound 27 shows the lowest-energy CT band centered at $400 \mathrm{~nm}$, due to the presence of both electron-donating dioxole substituent and electron-accepting $\left.\left(\mathrm{CF}_{3}\right)_{2}-\mathrm{Ar}\right)$ and benzothiadiazole groups, which give rise to strong charge-transfer transitions.

\begin{tabular}{|c|c|c|c|}
\hline & \multirow{2}{*}{$\begin{array}{c}\text { Absorption } \\
\lambda_{\text {abs }}{ }^{\mathrm{a}} / \mathrm{nm}\left(\varepsilon 10^{3} / \mathrm{M}^{-1} \mathrm{~cm}^{-1}\right)\end{array}$} & \multicolumn{2}{|c|}{ Emission at $298 \mathrm{~K}^{\mathrm{a}}$} \\
\hline & & $\lambda_{\mathrm{em}}{ }^{\mathrm{a}} / \mathrm{nm}$ & $\phi a, b$ \\
\hline 9 & $\begin{array}{c}306(5.8), 316(7.0), 358 \\
(3.0)\end{array}$ & 468 & 0.88 \\
\hline 17 & $\begin{array}{c}266(7.2), 308(6.1), 318 \\
(5.7), 376(2.3)\end{array}$ & 530 & 0.79 \\
\hline 19 & $\begin{array}{c}284(19.4), 306(18.2) \\
316(15.7), 376(7.5)\end{array}$ & 510 & 0.90 \\
\hline 20 & $\begin{array}{c}268(24.7), 378(39.0), \\
316(24.8), 326(28.4), \\
344(36.9), 382(6.3)\end{array}$ & $530^{d}$ & nd \\
\hline 24 & $\begin{array}{c}270(11.7), 320(3.3), 384 \\
\text { (1.9) }\end{array}$ & 492 & 0.53 \\
\hline 26 & $\begin{array}{c}272(18.1), 312(10.8) \\
320(9.8), 362(10.8)\end{array}$ & 449 & 0.89 \\
\hline 27 & $\begin{array}{c}291(5.9), 318(3.4), 400 \\
\text { (3.4) }\end{array}$ & 555 & 0.19 \\
\hline 29 & $\begin{array}{c}250(6.6), 333(6.3), 383 \\
(1.9)\end{array}$ & 503 & 0.42 \\
\hline
\end{tabular}

Interestingly, the seleno-derivative $\mathbf{2 9}$ displays similar absorption profile than its sulfur analogue 9, with absorption bands corresponding to ${ }^{1}\left(\pi-\pi^{*}\right)$ transitions on the tertbutylphenyl substituent of the benzoselenodiazole core and at lower-energy, a moderately intense band arising from the charge-transfer transition (Figure 3). Notably, compared with 9 the seleno-derivative 29 exhibits a large red-shift of the absorption bands belonging to the benzoselenodiazole core and a moderately bathochromic effect of the CT transitions, a feature in agreement with previous reports on related benzoselenodiazole compounds. ${ }^{23 b, 25}$ 


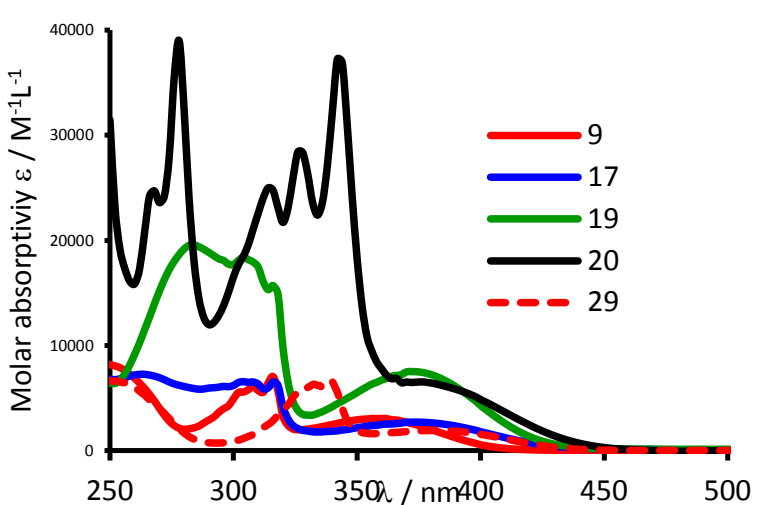

Figure 3. Absorption Spectra in $\mathrm{CH}_{2} \mathrm{Cl}_{2}$ at $298 \mathrm{~K}\left(\mathrm{C} \approx 10^{-5} \mathrm{M}\right)$ of the Mono-Substituted Compounds 9 (red line), 17 (blue line), 19 (green line), 20 (black line) and 29 (red dotted line).

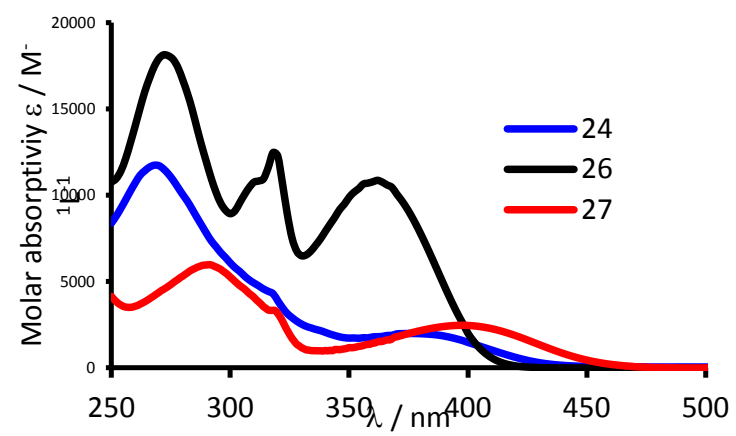

Figure 4. Absorption Spectra in $\mathrm{CH}_{2} \mathrm{Cl}_{2}$ at $298 \mathrm{~K}\left(\mathrm{C} \approx 10^{-5} \mathrm{M}\right)$ of the Di-Substituted Compounds 24 (blue line), 26 (black line) and $\mathbf{2 7}$ (red line).

The emission spectra of 9, 17, 19, 20, 24, 26, 27 and 29 are shown in Figure 5 and the emission data are compiled in Table 2. Except compound 20, all investigated compounds are strongly emissive in dichloromethane solution at room temperature. Remarkably, they exhibit good to excellent photoluminescence quantum yield $(\Phi)$ in solution as high as 90 $\%$ (19), whatever the nature of the substituent. Interestingly, the emission color goes from the blue ( $\lambda_{\mathrm{em}}=449 \mathrm{~nm}$ for 26) to the red $\left(\lambda_{\mathrm{em}}=555 \mathrm{~nm}\right.$ for 27 ) part of the spectrum, strongly depending on the nature of the incorporated aryl group on the benzothiadiazole core. The emission wavelength is fine-tuned by changing the electronic richness of the system and/or by introducing an extended $\pi$-system (fluorene, pyrene), as well as by replacing the sulfur atom by Se (9 vs. 29). The emission can be controlled by the CT transitions. For instance, the multi-polar derivative $\mathbf{2 7}$ displays the more red-shifted emission, consistently with CT absorption bands at lowerenergy. However, this red-shifted fluorescence is accompanied with a decrease of the photoluminescence quantum yield $(\Phi=19 \%)$, in agreement with the energy gap law. Compounds $\mathbf{9}$ and $\mathbf{2 6}$ display a blue emission, while $\mathbf{1 7}$ and 19 bearing an electron donating aryl or a fluorenyl group, respectively, emit in the orange-red region of the spectrum. The benzoselenodiazole $\mathbf{2 9}$ displays luminescence with a maximum at $503 \mathrm{~nm}$, red-shifted by about $35 \mathrm{~nm}$ with respect to the analogue 9, a feature comparable to that reported for related benzoselenodiazole compounds. ${ }^{23 b, 25}$

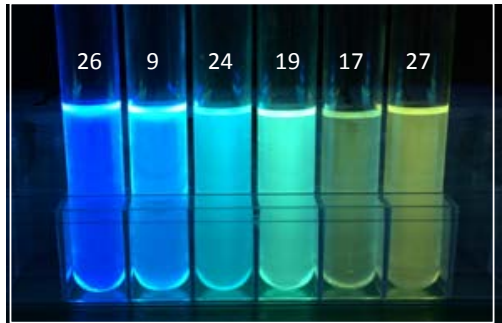

Photograph of 2,1,3-Benzothiadiazole Derivatives in $\mathrm{CH}_{2} \mathrm{Cl}_{2}$ Solution under $350 \mathrm{~nm}$ Irradiation

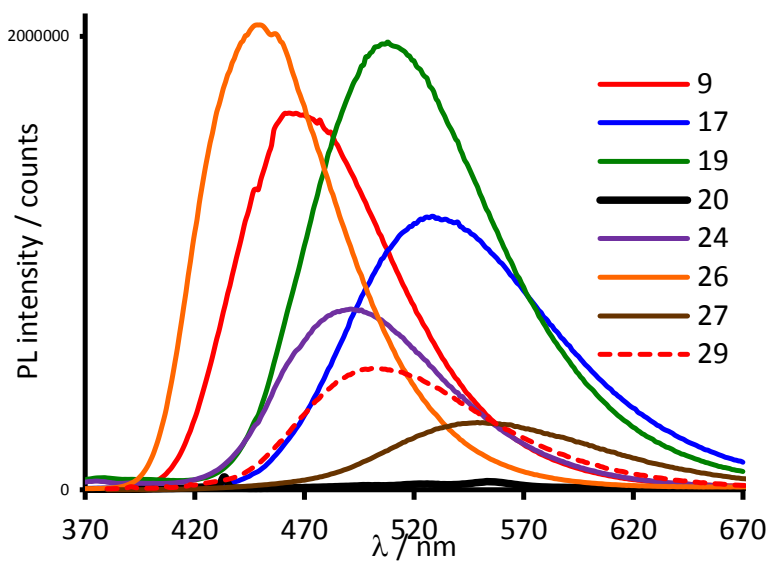

Figure 5. Emission Spectra in $\mathrm{CH}_{2} \mathrm{Cl}_{2}$ at $298 \mathrm{~K}\left(\mathrm{C} \approx 10^{-5} \mathrm{M}\right)$ of $\mathbf{9}$ (red line), 17 (orange line), $\mathbf{1 9}$ (pink line), $\mathbf{2 0}$ (black line), $\mathbf{2 4}$ (green line), $\mathbf{2 6}$ (blue line), $\mathbf{2 7}$ (brown line) and $\mathbf{2 9}$ (red dotted line), with $\lambda_{\mathrm{ex}}=350 \mathrm{~nm}$.

Note that compound $\mathbf{2 0}$ is non-emissive in fluid solution. This behavior can be explained by the presence of the pyrenyl group since pyrenes are known to be subject to self-quenching through the formation of aggregates or excimers in solution. Interestingly, the luminescence of $\mathbf{2 0}$ can be turned-on in the solid state. The solid-state fluorescence, measured on a drop casted film at $298 \mathrm{~K}$ (from dichloromethane solution), is characterized by a broad emission band centered at $530 \mathrm{~nm}$, likely originated from the excimer state (Figure 6). ${ }^{26}$

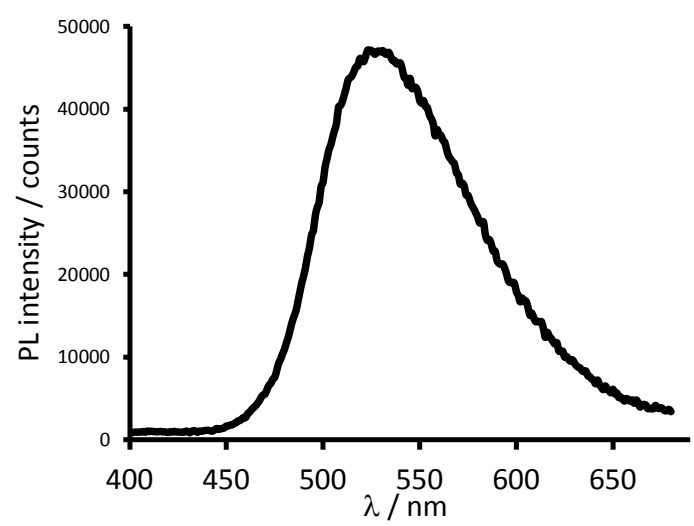

Figure 6. Emission Spectrum of $\mathbf{2 0}$ in a Drop Cast Film from $\mathrm{CH}_{2} \mathrm{Cl}_{2}$ solution, with $\lambda_{\text {ex }}=$ $350 \mathrm{~nm}$. 


\section{Conclusions}

In summary, 2,1,3-benzothiadiazole and 2,1,3benzoselenadiazole can be efficiently arylated at C4/C7 positions via palladium catalyzed $\mathrm{C}-\mathrm{H}$ bond activation. Simple phosphine-free palladium acetate associated to KOAc as base in DMA was found to be the best reaction conditions. A wide range of functions such as methoxy, chloro, formyl, propionyl, benzoyl, ester, nitrile, trifluoromethyl or nitro on the aryl bromide is tolerated. Some sterically hindered, $\pi$-extended and heteroaromatic aryl bromides have also been employed successfully, demonstrating the potential of this methodology for the preparation of organic materials. Interestingly, this method allows the introduction of aryl substituents with different electronic properties in one step resulting in a fine modulation of the fluorescence wavelength with emission colors covering the blue to the red part of the visible spectrum. The combination of these photophysical effects make such materials especially interesting for photovoltaic and OLED applications.

\section{Conflicts of interest}

There are no conflicts to declare.

\section{Acknowledgements}

We thank the Algerian "Ministry of Higher Education and Scientific Research" for a fellowship to I.I. We thank CNRS and "Rennes Metropole" for providing financial support.

\section{Notes and references}

1. N. J. Findlay, B. Breig, C. Forbes, A. R. Inigo, A. L. Kanibolotsky and P. J. Skabara, J. Mater. Chem. C, 2016, 4, 3774-3780.

2. Y. Wu and W. Zhu, Chem. Soc. Rev., 2013, 42, 2039-2058.

3. B. A. D. Neto, P. H. P. R. Carvalho and J. R. Correa, Acc. Chem. Res., 2015, 48, 1560-1569.

4. a) J. E. Barnsley, G. E. Shillito, C. B. Larsen, H. van der Salm, L. E. Wang, N. T. Lucas and K. C. Gordon, J. Phys. Chem. A, 2016, 120, 1853-1866; b) L. Chen, X. Li, W. Ying, X. Zhang, F. Guo, J. Li and J. Hua, Eur. J. Org. Chem., 2013, 2013, 1770-1780.

5. M. Velusamy, K. R. Justin Thomas, J. T. Lin, Y.-C. Hsu and K.-C. Ho, Org. Lett., 2005, 7, 1899-1902.

6. M. Wang, X. Hu, P. Liu, W. Li, X. Gong, F. Huang and Y. Cao, J. Am. Chem. Soc., 2011, 133, 9638-9641.

7. a) Y. Geng, A. C. A. Chen, J. J. Ou, S. H. Chen, K. Klubek, K. M. Vaeth and C. W. Tang, Chem. Mater., 2003, 15, 4352-4360; b) S.i. Kato, T. Matsumoto, T. Ishi-i, T. Thiemann, M. Shigeiwa, H. Gorohmaru, S. Maeda, Y. Yamashita and S. Mataka, Chem. Commun., 2004, 2342-2343; c) X. Zhang, H. Gorohmaru, M. Kadowaki, T. Kobayashi, T. Ishi-i, T. Thiemann and S. Mataka, J. Mater. Chem., 2004, 14, 1901-1904; d) D. Aldakov, M. A. Palacios and P. Anzenbacher, Jr., Chem. Mater., 2005, 17, 52385241; e) M. Velusamy, K. R. J. Thomas, J. T. Lin and Y. S. Wen, Tetrahedron Lett., 2005, 46, 7647-7651; f) M. Velusamy, K. R. J. Thomas, J. T. Lin, Y.-C. Hsu and K.-C. Ho, Org. Lett., 2005, 7, 1899-1902; g) M. Haussler, Y. P. Lok, M. Chen, J. Jasieniak, R.
Adhikari, S. P. King, S. A. Hague, C. M. Forsyth, K. Winzenberg, S. E. Watkins, E. Rizzardo and G. J. Wilson, Macromolecules, 2010, 43, 7101-7110; h) H. Zhang, X. Wan, X. Xue, Y. Li, A. Yu and Y. Chen, Eur. J. Org. Chem., 2010, 1681-1687; i) L. Han, X. Zu, Y. Cui, H. Wu, Q. Ye and J. Gao, Org. Electron., 2014, 15, 15361544; j) X. Yang, J. Zhao, L. Wang, J. Tian and L. Sun, RSC Adv., 2014, 4, 24377-24383; k) J. E. Donaghey, A. Armin, P. L. Burn and P. Meredith, Chem. Commun., 2015, 51, 14115-14118; I) J. Geng, Y. Dai, X.-X. Wang, M.-Y. Hu, T. Tao and W. Huang, Tetrahedron, 2015, 71, 654-662; m) K. Zhu, C. A. O'Keefe, V. N. Vukotic, R. W. Schurko and S. J. Loeb, Nat. Chem., 2015, 7, 514519; n) D. L. Crossley, I. Vitorica-Yrezabal, M. J. Humphries, M. L. Turner and M. J. Ingleson, Chem. Eur. J., 2016, 22, 12439-12448; o) L. Wang, W. Huang, R. Li, D. Gehrig, P. W. M. Blom, K. Landfester and K. A. I. Zhang, Angew. Chem. Int. Ed., 2016, 55, 9783-9787; p) R. Li, Z. J. Wang, L. Wang, B. C. Ma, S. Ghasimi, H. Lu, K. Landfester and K. A. I. Zhang, ACS Catal., 2016, 6, 11131121; q) C. Song, Y. Ling, L. Jin, M. Zhang, D.-L. Chen and Y. He, Dalton Trans., 2016, 45, 190-197.

8. a) K. R. J. Thomas, J. T. Lin, M. Velusamy, Y.-T. Tao and C.-H. Chuen, Adv. Funct. Mater., 2004, 14, 83-90; b) G. Qian, Z. Zhong, M. Luo, D. Yu, Z. Zhang, D. Ma and Z. Y. Wang, J. Phys. Chem. C, 2009, 113, 1589-1595; c) G. Qian, Z. Zhong, M. Luo, D. Yu, Z. Zhang, Z. Y. Wang and D. Ma, Adv. Mater., 2009, 21, 111-116; d) Y.-H. Chen, L.-Y. Lin, C.-W. Lu, F. Lin, Z.-Y. Huang, H.-W. Lin, P.-H. Wang, Y.-H. Liu, K.-T. Wong, J. Wen, D. J. Miller and S. B. Darling, J. Am. Chem. Soc., 2012, 134, 13616-13623; e) C. Tong, J. Chang, J. M. Tan, G. Dai, K.-W. Huang, H. S. O. Chan and C. Chi, Org. Biomol. Chem., 2013, 11, 5683-5691; f) S.-i. Kato, T. Furuya, M. Nitani, N. Hasebe, Y. le, Y. Aso, T. Yoshihara, S. Tobita and Y. Nakamura, Chem. Eur. J., 2015, 21, 3115-3128; g) S.-J. Woo, S. Park, J.-E. Jeong, Y. Hong, M. Ku, B. Y. Kim, I. H. Jang, S. C. Heo, T. Wang, K. H. Kim, J. Yang, J. H. Kim and H. Y. Woo, ACS Appl. Mater. Interfaces, 2016, 8, 15937-15947.

9. K. Shimizu, Y. Minami, Y. Nakao, K.-i. Ohya, H. Ikehira and T. Hiyama, Chem. Lett., 2013, 42, 45-47.

10. a) H. Langhals, P. Knochel, A. Walter and S. Zimdars, Synthesis, 2012, 44, 3465-3477; b) S. Zimdars, H. Langhals and P. Knochel, Synthesis, 2011, 2011, 1302-1308.

11. N. Nakamura, Y. Tajima and K. Sakai, Heterocycles, 1982, 17, 235-245.

12. a) A. Ohta, Y. Akita, T. Ohkuwa, M. Chiba, R. Fukunaga, A. Miyafuji, T. Nakata, N. Tani and Y. Aoyagi, Heterocycles, 1990, 31, 1951-1958; b) Y. Aoyagi, A. Inoue, I. Koizumi, R. Hashimoto, K. Tokunaga, K. Gohma, J. Komatsu, K. Sekine, A. Miyafuji and J. Kunoh, Heterocycles, 1992, 33, 257-272.

13. a) F. Kakiuchi and T. Kochi, Synthesis, 2008, 3013-3039; b) L. Ackermann, R. Vicente and A. R. Kapdi, Angew. Chem. Int. Ed., 2009, 48, 9792-9826; c) F. Bellina and R. Rossi, Tetrahedron, 2009, 65, 10269-10310; d) X. Chen, K. M. Engle, D.-H. Wang and J.-Q. Yu, Angew. Chem. Int. Ed., 2009, 48, 5094-5115; e) T. W. Lyons and M. S. Sanford, Chem. Rev., 2010, 110, 1147-1169; f) E. M. Beck and M. J. Gaunt, Top. Curr. Chem., 2010, 292, 85-121; g) T. Satoh and M. Miura, Synthesis, 2010, 3395-3409; h) C.-L. Sun, B.-J. Li and Z.-J. Shi, Chem. Commun., 2010, 46, 677-685; i) S. H. Cho, J. Y. Kim, J. Kwak and S. Chang, Chem. Soc. Rev., 2011, 40, 5068-5083; j) N. Kuhl, M. N. Hopkinson, J. Wencel-Delord and F. Glorius, Angew. Chem. Int. Ed., 2012, 51, 10236-10254; k) B.-J. Li and Z.-J. Shi, Chem. Soc. Rev., 2012, 41, 5588-5598; I) M. C. White, Synlett, 2012, 23, 2746-2748; m) J. Yamaguchi, A. D. Yamaguchi and K. Itami, Angew. Chem. Int. Ed., 2012, 51, 89609009; n) S. I. Kozhushkov and L. Ackermann, Chem. Sci., 2013, 4, 
886-896; o) R. Rossi, F. Bellina, M. Lessi and C. Manzini, Adv. Synth. Catal., 2014, 356, 17-117; p) M. Zhang, Y. Zhang, X. Jie, H. Zhao, G. Li and W. Su, Org. Chem. Front., 2014, 1, 843-895; q) M. R. Yadav, R. K. Rit, M. Shankar and A. K. Sahoo, Asian J. Org. Chem., 2015, 4, 846-864; r) K. Hirano and M. Miura, Chem. Lett., 2015, 44, 868-873; s) K. Yuan, J.-F. Soulé and H. Doucet, ACS Catal., 2015, 5, 978-991; t) C. B. Bheeter, L. Chen, J.-F. Soulé and H. Doucet, Catal. Sci. Technol., 2016, 6, 2005-2049.

14. J. Zhang, W. Chen, A. J. Rojas, E. V. Jucov, T. V. Timofeeva, T. C. Parker, S. Barlow and S. R. Marder, J. Am. Chem. Soc., 2013, 135, 16376-16379.

15. a) M. Lafrance, C. N. Rowley, T. K. Woo and K. Fagnou, J. Am. Chem. Soc., 2006, 128, 8754-8756; b) M. Lafrance, D. Shore and K. Fagnou, Org. Lett., 2006, 8, 5097-5100; c) T. Yan, L. Zhao, M. He, J.-F. Soulé, C. Bruneau and H. Doucet, Adv. Synth. Catal., 2014, 356, 1586-1596; d) M. He, J.-F. Soulé and H. Doucet, ChemCatChem, 2014, 6, 1824-1859; e) M. He, J.-F. Soulé and H. Doucet, ChemCatChem, 2015, 7, 2130-2140.

16. X. Zhang, Y. Gao, S. Li, X. Shi, Y. Geng and F. Wang, J. Polym. Sci., Part A: Polym. Chem., 2014, 52, 2367-2374.

17. X. Kang, J. Zhang, D. O'Neil, A. J. Rojas, W. Chen, P. Szymanski, S. R. Marder and M. A. El-Sayed, Chem. Mater., 2014, 26, 44864493.

18. C.-Y. He, C.-Z. Wu, F.-L. Qing and X. Zhang, J. Org. Chem., 2014, 79, 1712-1718.

19. J. Zhang, T. C. Parker, W. Chen, L. Williams, V. N. Khrustalev, E. V. Jucov, S. Barlow, T. V. Timofeeva and S. R. Marder, J. Org. Chem., 2016, 81, 360-370.

20. I. Idris, F. Derridj, J.-F. Soulé and H. Doucet, Adv. Synth. Catal., 2017, 359, 2448-2456.

21. CCDC 1564784 (18), CCDC 577123 (20), CCDC 1564844 (26) and CCDC 1576377 (30) contain the supplementary crystallographic data for this paper. These data can be obtained free of charge from The Cambridge Crystallographic Data Centre.

22. a) A. Skhiri, R. Ben Salem, J.-F. Soulé and H. Doucet, ChemCatChem, 2017, 9, 2895-2913; b) A. Skhiri, R. B. Salem, J.F. Soulé and H. Doucet, Chem. Eur. J., 2017, 23, 2788-2791.

23. a) W.-Q. Zhang, Q.-Y. Li, Q. Zhang, Y. Lu, H. Lu, W. Wang, X. Zhao and X.-J. Wang, Inorg. Chem., 2016, 55, 1005-1007; b) M. Velusamy, K. R. J. Thomas, J. T. Lin and Y. S. Wen, Tetrahedron Lett., 2005, 46, 7647-7651.

24. a) B. A. D. Neto, A. S. A. Lopes, G. Ebeling, R. S. Gonçalves, V. E. Costa, F. H. Quina and J. Dupont, Tetrahedron, 2005, 61, 1097510982; b) P. Wei, L. Duan, D. Zhang, J. Qiao, L. Wang, R. Wang, G. Dong and Y. Qiu, J. Mater. Chem., 2008, 18, 806-818; c) R. Misra, P. Gautam, T. Jadhav and S. M. Mobin, J. Org. Chem., 2013, 78, 4940-4948; d) T. Jadhav, B. Dhokale, Y. Patil, S. M. Mobin and R. Misra, J. Phys. Chem. C, 2016, 120, 24030-24040; e) T. O. Lopes, D. A. Silva Filho, A. A. Lapis, H. C. Oliveira and B. A. Neto, J. Phys. Org. Chem., 2014, 27, 303-309.

25. S. Mondal, M. Konda, B. Kauffmann, M. K. Manna and A. K. Das, Cryst. Growth Des., 2015, 15, 5548-5554.

26. F. M. Winnik, Chem. Rev., 1993, 93, 587-614. 